\title{
Treating Posttraumatic Stress Disorder in South Africa: An Integrative Model Grounded in Case-Based Research
}

\author{
David J. A. Edwards \\ Rhodes University, South Africa
}

Address correspondence to Professor David J.A. Edwards, Department of Psychology, Rhodes University, Grahamstown, 6140, South Africa. E-mail: d.edwards@ru.ac.za.

The article presents a model for formulating and planning treatment for post-traumatic stress disorder (PTSD) in South Africa derived from the existing literature and in conjunction with a review of a series of studies of cases treated using the guidelines of Ehlers and Clark's cognitive therapy. It is argued that the construction of psychotherapies (or even components of psychotherapy) for PTSD in terms of traditional categories ("psychodynamic", "cognitive-behavioural”, "narrative" etc.) is misleading and unhelpful. Instead, superordinate concepts derived from thinking about evidence-based practice provide a more grounded focus on the practical issues faced by therapists treating PTSD. These concepts, which include competences and metcacompetences, therapist responsiveness, stages of therapy and case formulation, provide a basis for a genuinely integrative approach. The proposed model suggests seven broad areas of clinical focus for work with PTSD which can be arranged at three levels of priority: level 1 crisis intervention and stabilization; level 2 promoting engagement with treatment, and level 3 selection, sequencing and timing of active treatment interventions. Material from the case series is used to illustrate the application of the model.

\section{Introduction: Confusion of Tongues in the Naming of Therapies for PTSD}

For the treatment of clients with posttraumatic stress disorder (PTSD) there appears to be a bewildering array of options. Clinicians discuss the merits and demerits of "psychodynamic therapy", "narrative therapy", or "cognitive-behaviour therapy" (CBT) and may express their preference for "hypnotherapy," "art therapy," "exposure-based treatment," "cognitive therapy" (CT), or "eye-movement desensitization and reprocessing" (EMDR). Even within CT and CBT there is a range of apparently different treatments with different names, many of which have been described in treatment manuals and evaluated in randomized controlled trials (RCTs) (Chemtob, Tolin, Van Der Kolk, \& Pitman, 2000; Ehlers, Clark, Hackmann, McManus, \& Fennell, 2005; Grunert, Weis, Smucker, \& Christianson, 2007; Kubany et al., 2004; Resick, Nishith, Astin, Weaver \& Feuer, 2002; Najavits, 2004)

However, the names of therapies for PTSD are misleading, because, although specific techniques are specific to particular approaches, there is considerable commonality between them. As models evolve, they expand their technical range to dea with clinical problems not handled by existing interventions, often drawing on techniques from other models. Whatever their training or allegiance, therapists are presented with the same kind of challenges in helping clients to reduce intrusive re-experiencing and to rebuild their lives. Most models would include interventions like asking clients to tell the story of a traumatic event, helping them to engage emotionally with their experience of what happened, identifying the personal meanings of different aspects of the trauma or examining the rational basis for guilt inducing beliefs. Thus Ehlers and Clark's CT for PTSD (Ehlers \& Clark, 2000; Clark \& Ehlers, 2005) includes techniques traditionally regarded as cognitive such as cognitive restructuring and the use of thought records, but these may play a relatively small role in treatment. Similarly, although the term EMDR features the induction of eye-movements, the EMDR protocol includes a comprehensive set of principles common to other models. In some studies, the EMDR protocol was equally effective with or without the induction of eye-movements (Lohr, Lilienfeld, Tolin, \& Herbert, 1999).

Integration of approaches is illustrated by the five components of the Wits trauma model (Eagle, 1998, 2000) widely used in South Africa: (1) Telling/retelling the story, (2) Normalizing the symptoms, (3) Addressing self-blame or survivor guilt (restoring self-respect), (4) Encouraging mastery, and (5) Facilitating creation of meaning. Eagle points out that aspects of each of these components have been described within either the psychodynamic or the cognitive-behavioural literature or both. However, although both literatures need to be drawn on as a basis for treating PTSD, models for treating PTSD do not typically use the term "integrative" in their names.

In work with children with PTSD, Leibowitz-Levy (2005) found that most South African practitioners use an integrative approach. Many used the Wits model. Others included the Pynoos and Eth (1986) child interview (originally designed as a single session debriefing intervention). This begins by inviting expression and description through such methods as narrative, play or projective drawing. The therapist then helps the child explore what has happened and the personal meanings attached to it in order to encourage mastery, and finally uses what has emerged to promote more effective coping. Other therapists used

less structured approaches with the emphasis on facilitating the development of a narrative of the trauma, affirming the child's experience, engaging with feelings of shame and guilt and encouraging and affirming attempts at mastery" (Leibowitz-Levy, 2005, pp. 157-8).

Leibowitz-Levy (2005) used the Wits model integrated with the Pynoos and Eth interview. In the integrated model emphasis is on the quality of the therapist's relationship with the child, the use of expressive art. In her approach to treating PTSD, she also pays attention to "contextualising of the traumatic experi- 
ence within the individual's personal history and sense of self" (p. 158) by inviting children to make a series of drawings of "myself as I was," "myself in the trauma," and "myself now". This helps children find an identity beyond the trauma and might be considered an aspect of the "facilitating creation of meaning" component of the Wits model.

Despite the acceptance of integration, clinicians may still find it hard to negotiate the apparent diversity of models. This is not largely due to resistance to integration because, particularly in the field of traumatic stress, this has happened extensively. Many trauma specialists have been exposed to several modalities of therapy during training and there is a great deal of exchange of ideas internationally. Within specific models the mix may be somewhat different with respect to what is emphasized but there are no models which might be considered "pure" in having simple historical origins uninfluenced by developments in other areas of psychotherapy. Indeed, the search for such purity could be considered at the least narrow-minded and at most unethical since there is now abundant evidence that treatment needs to be draw on a range of different interventions.

\section{Psychotherapy traditions: Conflicts and confluences}

In South Africa, therapist allegiances to particular traditions perpetuate the exaggeration of differences between similar approaches. According to social identity theory (Foster, 1998), individuals identify with an "in-group" which sharpens its definition by favourable comparisons with an "out-group". Group members enhance their self-esteem by cultivating overly positive stereotypes of the in-group and overly negative stereotypes of the out-group. This kind of "instinctual territoriality" may be a legacy of evolution to which therapists are not immune (Dattilio \& Norcross, 2006). Since "pragmatic blending is explicitly anti-territorial," Dattilio and Norcross suggest, it "encounter[s] heavy resistance from those invested in owning or preserving ownership of ideas" (p.12). Thus training in particular categories of therapy often involves presenting other therapies in an unfavourable light and therapists' identities can become caught up in being a particular type of therapist, with a resultant distrust of other approaches.

The discourses of academic writing also perpetuate the oversimplified categorization of therapies. Textbooks categorize approaches for didactic purposes and students overlearn the names and potted definitions, unaware of the complexities that underlie them. So habitual are they that even those advocating integration perpetuate the simplistic discourses of the textbook. Thus, when Leibowitz-Levy recommends incorporating "elements of CBT and play therapy" (p. 157), she incorrectly implies that CBT therapists do not use play. The play therapy literature includes approaches that are not only interpretive and relational (in the psychodynamic tradition), but also non-directive (in the tradition of Axline, 1989) and structured and learning oriented (in line with CBT principles) (e. g. Kaduson \& Schaefer 2001; Schaefer, 1993; Schaefer \& Cangelosi, 2002). Knell's (1993) Cognitive-behavioural play therapy explicitly integrates play into CBT with children and Ronen (1997) provides further examples.

Eagle (2000) examines how components of the Wits model are consistent with concepts from within the psychodynamic and CBT literatures. "Telling the story," for example, can be understood psychodynamically, with Freud, as cathartic, "enabling the client to express the unexpressed feelings and fantasies associated with the trauma" (p. 308) and provides the client with the opportunity to "symbolize his/her experience verbally" and thus transform it into "secondary processed thought ... and thus more rational, reality-based, and comprehensible." However, these aspects can hardly be considered "psychodynamic" (rather than "cognitive-behavioural" or "person-centred" or any other specific approach), since any approach to trauma work would need to incorporate these basics (without necessarily using the terms "cathartic", "symbolize" and "secondary process"). Because clients seen by different kinds of therapists are all human beings subject to the same common psychological processes, similar concepts appear within different traditions and there is also an inevitable continuity between the ideas of earlier writers and contemporary theorists. Erdelyi (1985) has examined Freud's theories from this perspective.

The shifts in metaphors and models introduced by the information-processing age impacted on psychodynamic as well as on cognitive-behavioural theory. Bowlby's (1979) attachment theory using the information-processing language of, "internal working models" was taken up by Horowitz, a psychodynamic therapist, who has been a major contributor to the development of theory and practice in working with trauma (his 2001 Stress response syndromes is the fourth edition of a book first published in 1976). Langs (1996, p. 194), who attributes vulnerability to emotional disorders to "the inherited disease of a dysfunctional emotion-processing mind" also draws on the information processing metaphor in integrating evolutionary theory with psychodynamic theory.

An aspect that is constructed as particularly "psychodynamic" by Leibowitz-Levy (2005) and Eagle (2000) is attention to the therapeutic relationship. In the same way, in her explicitly psychodynamic work with a young woman who had been held captive and raped, Labe (2005, p. 179) writes that

rather than focussing on symptom alleviation, the therapy concentrated on providing a safe, containing relationship in which the meanings and unconscious resonances of the symptoms could be explored, interpreted and worked through.

Labe implies that an approach that was not psychodynamic would not do this and that there is a choice to be made between cultivating an experience of safety through the relationship and using specific techniques to alleviate symptoms.

This may be an appropriate critique of some CBT approaches and the rich diversity of psychodynamic theory relevant to the treatment of trauma is usefully reviewed by Schottenbauer, Glass, Arnkoff and Gray (2008). However, these kinds of insights have been integrated into a considerable amount of CBT literature. Focus on the therapeutic relationship appears later in CBT than in the psychodynamic traditions partly because CBT as a cohesive force only emerged in the 1970s. However, an early study found that psychoanalytic and behaviour therapists were comparable in terms of "communicating empathy and maintaining rapport" (Brunink \& Schroeder, 1979 , p. 573) and it is misleading to imply that the relationship has not been a focus of attention in CBT. Within Beck 's cognitive therapy,

the therapeutic relationship was always considered important ... but ... [because of] the impact of Rogers ... people training in cognitive therapy were assumed to have basic micro-skills and counselling skills [in establishing and maintaining a therapeutic relationship] (Gilbert \& Leahy, 2007, p. 5) .

For cognitive therapists, it is artificial to construct attention to the relationship and the use of technical interventions as incom- 
patible opposites since there is "a reciprocal (and perhaps synergistic) effect between the technical and relational aspects of ... therapy" (Newman, 2007, p. 167). It is already a quarter of a century since Arnkoff (1981) recommended that when cognitive therapists could not establish a working relationship with clients this needed to become a focus of the therapy. Safran (1984) integrated Sullivan's interpersonal fomulation methods and recommended that cognitive therapists attend to the feelings evoked in them by clients and use them to respond strategically. This was developed further in Safran and Segal's (1996) Interpersonal process in cognitive therapy and a comprehensive study of the identification and repair of ruptures in the therapeutic alliance (Safran \& Muran, 2000). Guidano and Liotti's (1984) integration of Bowlby's attachment theory with Beck's cognitive therapy contributed both to the developmental formulation of the client's difficulties and to the formulation of the therapist-client relationship. Liotti, $(1987,2007)$ offers detailed guidelines for how therapists could become aware of this and respond appropriately.

Leibowitz-Levy (2005, p. 157) also uses "psychodynamic" to refer to the work of "contextualising the impact of the trauma within the individual's history and integrating a sense of self altered by the traumatic experience." However, this significant aspect of treatment, conceptualized as part of posttraumatic growth by Calhoun and Tedeschi (2006), has been examined by writers from such a wide variety of perspectives (including narrative, and CBT) that it is misleading to call it "psychodynamic" if this is taken to imply an exclusive orientation.

\section{Evidence-based Practice: Beyond Ideological Allegiances}

The kind of discourse problems discussed above can be overcome by focusing on superordinate concepts that have emerged from the development of principles of accountability for the health professions around the concept of evidence-based practice (EBP). These create a common focus for examination and discussion of the pragmatic issues faced by all therapists working with PTSD. Some may shy away from EBP because they incorrectly interpret it to imply an obligation to use treatment manuals that have been shown to be effective in RCTs and to follow them slavishly. This was the implication of the term "empirically validated treatments" which, having been invented by researchers, was impractical and onerous for clinicians. However, this has been largely superceded by the concept of EBP, which is much more clinician-friendly and takes into account the contextual realities of practice.

EBP developed in medicine where it was defined as:

... the conscientious, explicit and judicious use of current best evidence in making decisions about the care of individual patients [which] means integrating individual clinical expertise with the best available external clinical evidence from systematic research (Sackett, Rosenberg, Gray, Haynes \& Richardson, 1996, p. 71).

Psychologists have often felt inappropriately constrained by concepts originating from medical practice, and make global criticisms of "the medical model". However, EBP is a broad and flexible set of principles which are helpful in guiding clinica practice in psychology. EBP in psychology involves "the integration of the best available research with clinical expertise in the context of patient characteristics, culture and preferences" (American Psychological Association, 2005, p. 5). Its adoption by the American Psychological Association (APA) following a report by a specially commissioned task force, acknowledged a pragmatic clinical perspective in a domain where debates are too often dominated by research-oriented priorities with limited clinical relevance.

The definition incorporates three important features. First, "research" is understood broadly to cover any systematic investigation yielding information relevant to evaluating what is appropriate practice. In addition to RCTs and experimental studies which test the theories on which treatments are based, relevant research includes qualitative studies of various kinds and systematic case studies, all of which can furnish information unobtainable from multivariate studies (Edwards, Dattilio, \& Bromley, 2004; Goodheart, 2005; Salkovskis, 2002). Second, the phrase "in the context of patient characteristics, culture and preferences," acknowledges that psychological interventions are delivered in specific contexts often quite different from those in which published studies were carried out. Third, the reference to "clinical expertise", recognizes that evidence from a clinician's own experience is part of the data on which clinical decisions are made.

\section{Competences and metacompetences}

Brands of therapy are often identified by particular kinds of interventions championed by their developers. Roth and Pilling (2008) use the term "competence" for a therapist's ability to deliver a specific intervention. Basic competences for any therapist include forming a relationship, negotiating a therapy contract, accurately empathizing with a client's experience, or accurately reflecting it back. In addition, specific models of treatment require specific competences. All treatments that have been systematically evaluated in controlled trials require manuals that specify therapist competences. These include not only CBT (e.g., McDonagh et al, 2005) but also experiential (e.g., Paivio \& Nieuwenberg, 2001) and psychodynamic therapies (such as those reviewed by Schottenbauer et al, 2008).

It is increasingly recognized that clinicians need specialized competences relevant to the kind of problem clients present with (Roth \& Pilling, 2008). Within the broad domain of CBT, it is not enough for a therapist to have a generic training. Treatments have become so specialized that the capacity to deliver evidence-based treatment for one clinical problem does not necessarily generalize to another. For example, Ehlers and Clark's (2000) treatment for PTSD includes specific procedures, such as a structured visit to the site of the traumatic event, or guiding the reliving of the trauma and using imagery techniques to restructure meaning, which might not be needed in the treatment of eating disorders.

However, therapy involves more than competences. There are few clients for whom treatment can be constructed by stringing together a series of techniques. Competences need to be supplemented by "metcompetences." These are

procedural rules that enable therapists to implement therapy in a coherent and informed manner, and to apply an intervention in a manner that is responsive to the needs of an individual client" (Roth \& Pilling, 2008, p. 140).

Whatever the form of therapy, this involves "the ability to use clinical judgement when implementing treatment models" and the "the capacity to adapt interventions in response to client feedback" (p. 139). Metcompetences are therefore the basis for therapist responsiveness. 


\section{Therapist responsiveness}

The concept of "therapist responsiveness" is increasingly used to capture therapists' application of this kind of procedura knowledge that cannot be acquired simply by reading research or even practitioner oriented literature. Whatever their approach, all therapists must

monitor the situation, . . choose a treatment that is appropriate for the client's problems, follow a strategy that is appropriate for the client's capacity, and intervene with techniques that are appropriate for the client's current state (Stiles, Honos-Webb \& Surko, 1998, p. 440).

This calls for ongoing responsiveness to the needs, limitations, strengths and resources of clients and to the changing context of their lives. Responsiveness "occurs on time scales that range from months to milliseconds" (Stiles et al, 1998, p. 440). This could involve, at the level of milliseconds, therapists picking up a client's sudden shift in mood and modulating their response appropriately, or, at the level of months, monitoring a client's growing independence (or failure to develop independence) and taking this into account in intervention planning.

Stiles et al. (1998, p. 440) contrast a "responsive" approach to delivering treatment with a "ballistic" one. The latter implies a standardized treatment delivery to every client. In administering an antibiotic, for example, doctors typically instruct patients to complete the five day course. The use of the term "manualized treatment" is sometimes taken to imply a ballistic approach to psychotherapy delivery. However this is misleading. Discussing their treatment manual for childhood anxiety disorders, Kendall, Aschenbrand, and Hudson (2003, p. 84) recommend finding a "middle ground" between structure and flexibility based on "using the manual as a guide and with integrity yet allowing it become vibrant and alive when put into practice" (p. 84).

Roth and Pilling (2008, p. 137) also found that although some CBT manuals were quite prescriptive, others provided a great deal of flexibility and assumed that general clinical guidelines and specific interventions would be applied in a manner based on practitioners' "prior clinical experience". Similarly, Stiles et al (1998, p. 447) concluded that "therapists in skilfully conducted manualized treatments, do appear to deliver process components responsively, depending on client characteristics" and that many manuals

... demand skill and clinical judgement about how and when to apply the specified techniques. They recommend close attention to the way clients respond to interventions and to the developing context of therapy and they suggest different tactics based on clients' emerging requirements (p. 446).

In everyday practice where few clinicians follow manuals slavishly, responsiveness is part of the territory of being a therapist. In case supervision there is typically considerable focus on aspects of responsiveness because it is so central to the effective delivery of any form of therapy. Supervisors help supervisees with the timing of interventions, for example, whether these are in the form of interpretations (psychodynamic), expressive methods (experiential therapy) or specific cognitive or behavioural interventions (CBT). This means that, even if the same treatment approach is used, no two clients ever receive identical treatments since, the delivery will be different because of therapist responsiveness.

\section{Case formulation}

One important source of therapist responsiveness is case formulation. This provides the means of "developing interventions on the basis of hypotheses about the psychological processes that underpin specific presentations" (Roth and Pilling, 2008, p. 129). Within many therapy orientations it is recognized that

the key ingredient of therapeutic success is the matching of the therapist's interventions to the patient's central underlying psychological problem (Persons, Curtis, \& Silberschatz, 1991, p. 608).

Case formulation takes place at the end of the assessment phase and provides the basis for planning interventions. However it is also an ongoing activity. As new information comes to light in the form of new disclosures by the client or the manner in which the client responds to the therapist's interventions, the formulation is likely to be refined, elaborated or even radically altered (e. g. Waller, Kennerley \& Ohanian, 2007).

Formal case formulation is a skilled activity. Specialists in case formulation who had written articles or offered training workshops on it gave better quality formulations than both novice and experienced practitioners (Eells, Lombart, Kendjelic, Turner, \& Lucas, 2005). Surprisingly, experienced practitioners (psychodynamic and CBT) did not perform better than novices. Persons \& Bertagnolli (1999) found that CBT therapists who examined an assessment summary missed about a third of the problems that might serve as a focus for therapy, and inter-rater reliability of ratings of schemas averaged only .37. This accords with findings of other studies which show that most practitioners do not make systematic or explicit case formulations and the lack of standardization in case formulation procedures even within the broad "psychodynamic" and "cognitive-behavioural" traditions (Eells, 1997). Nevertheless, when psychodynamic and CBT formulations are based on well structured and focused models, there can be considerable commonality between them (Persons et al, 1991).

There is an emerging consensus among PTSD theorists about the underlying nature of the disorder. There is general agreement that the PTSD client has not been able to integrate information about a traumatic episode associated with an overwhelmingly intense emotional charge into the normal cognitive structures representing the self in the world, referred to as autobiographical memory (Conway \& Pleydell-Pearce, 2000). This information, whether described as suppressed, repressed, dissociated, fragmented or avoided, is the source of the distressing re-experiencing and arousal symptoms that characterize PTSD and motivate avoidance behaviours. The associated emotional distress may include a range of emotions including fear, anger, grief, guilt and shame, each of which is related to specific meanings which may be unique to the individual (for a fuller exposition see Edwards, 2005). Several factors render some individuals more vulnerable to developing PTSD, for example, experience of past traumas and being raised in a dysfunctional family (for a fuller review, see Edwards, Sakasa \& van Wyk, 2005). Several factors contribute to the maintenance of the disorder including lack of social support, and systematic avoidance of thinking or talking about what happened (for a fuller review, see Edwards, 2005). This consensus means that there is likely to be considerable overlap between the way cases of PTSD are formulated by therapists trained in different models.

\section{Timing and stage of therapy}

With PTSD, monitoring the stage that a client is at is an important aspect of ongoing formulation. Most models would agree that the first task of the therapist is to establish a relationship with clients in which they feel safe and able to trust the reliability, direction, and expertise of the therapist. The second is to 
help clients tell the story of what happened (whether in narrative, imaginal reliving or through expressive methods), to identify the personal meanings associated with the most intense distress, and to work to change those meanings into a more productive, self-enhancing and future oriented direction ("working through" or "emotional processing"). The third task, built on the second, is to help clients return to a full, active and involved life which gives them meaning in the present and hope for the future. In working with PTSD, the timing of interventions is a central feature of therapist responsiveness. As Herman (2001) observes, "A form of therapy that may be useful for a patient at one stage may be of little use or even harmful to the same patient at another stage" (p. 256).

Therefore, Smucker, Grunert and Weiss (2003) suggest an algorithmic approach to planning treatment based on the stage that has been reached. Herman (2001) observes that over a century ago, Janet recognized three stages: (1) stabilization and symptom oriented treatment, (2) exploration of traumatic events and (3) personality reintegration and rehabilitation. These are similar to Herman's own three broad stages which she calls safety, remembrance and mourning, and reconnection. Ford, Courtois, Steele, van der Hart and Nijenhuis (2005) present a similar three stage model for treating complex posttraumatic cases (alliance formation and stabilization, trauma processing, and functional reintegration), while Phillips \& Frederick's (1995) SARI model for hypnotherapy has a similar structure although it has four stages: $S$ - Safety, Stabilization, Strengthening; A - Activation of trauma memory and resources to cope with it; $\mathrm{R}$ - renegotiate trauma, resolve symptoms, reassociate dissociated experiences; I - Integration of personality functioning. The difference in the number of stages is unimportant because they effectively divide Herman's second stage into two, and each stage involves several activities that could be classified into substages.

Although therapists should begin at the first stage, they often need to return to activities in the earlier stages as new problems present themselves. For this reason, Ford et al (2005), Herman (2001), and Philips and Frederick (1995) use the metaphor of a spiral rather than a linear progression through the stages. They also recognized that, where there has been longstanding exposure to extreme situations of abuse or relational dysfunction or multiple traumas, the process of therapy is likely to be more complex and to take longer, and challenges to case formulation and treatment planning are even greater where there are extreme manifestations of dissociation as in some complex trauma presentations including dissociative identity disorder (Steele, van her Hart \& Nijenhuis, 2005).

\section{A Series of Systematic Case Studies of the Treatment of PTSD}

This article presents a model for evidence-based responsive intervention for PTSD in South Africa. It is based on the findings of a research programme with a case study methodology. The clinicians are PhD students or Master's students in Clinical or Counselling Psychology who treated cases of PTSD based on Ehlers and Clark's CT.

This therapy approach was chosen for three reasons. First, it can be delivered outside of the research clinics of the developers as it is manualized and the author has had the opportunity to interact with Ehlers, Clark and members of their group and to view videos of complete therapies. Second, it is based on a comprehensive theory which integrates much of what is covered in other theories of PTSD and offers a systematic explanation of the factors maintaining the disorder. The theory is suffi- ciently clinically grounded that it can serve as a basis for the detailed formulation of each new case. Third, the theory serves as a basis for the systematic selection of interventions to test the formulation and to break the cycles maintaining the disorder. Fourth, a comprehensive range of interventions is available, but, because treatment planning is formulation driven, the model is not prescriptive about what should happen in any particular session and clinicians are expected to be responsive to the needs of the client and the emergent process of therapy. Finally, it is the treatment for PTSD for which there is currently the best evidence. It has been evaluated in a case series, in RCTs and in an applied setting in Northern Ireland after the Omagh bomb. The obtained effect sizes (as high as 2.8 ) are markedly higher than those reported for many other treatments evaluated in RCTs. The large effect sizes are due to the drop out rate being very low and the efficacy of the active treatment ingredients.

Systematic case studies are written following the principles set out by Fishman (2005). Each includes a summary of the assessment and case formulation, a narrative of the process of the treatment and summary of the self-report responses either in tables of graphs. In preparation for the writing, a comprehensive assessment is conducted. The assessment information is used to derive a case formulation which identifies the predisposing, precipitating and maintaining factors relevant to the symptoms of PTSD and of other presenting problems including depression. The case formulation, in conjunction with Ehlers and Clark's model, is used as the basis for a broad treatment plan. Treatment sessions are audio-recorded. In the first, a collaborative contract is made with the client in terms of the case formulation and treatment plan. Treatment is implemented, and the response of the client is reviewed in supervision session by session. The formulation is reexamined so that the selection of interventions is in line with the treatment model as well as responsive to the needs and context of the client. Clients complete selected self-report scales, some at every session and some less frequently, as a means of monitoring their experience and the impact of the treatment.

The model for ongoing case formulation and responsive treatment planning for PTSD which is presented in Figure 1 was developed on the basis of six such systematic case studies. With one exception, they were black Africans living in South Africa (although Bongi was from Swaziland, and Grace from Zimbabwe). Langu (21) developed PTSD after identifying the body of his brother who had died in a car accident in which the car caught fire, and was so depressed that he could not do any productive academic work (Karpelowsky \& Edwards, 2005). Oratilwe (23) had been raped by her boyfriend and had spoken to no-one about what happened until, two years later, she saw the clinician in response to a notice posted in the street (Davidow \& Edwards, 2007). Zanele (15) had been raped twice in the township when visiting her disabled father. On several occasions, she had run out of the classroom in a panicy state (Payne \& Edwards, 2007). Mark (35), the only white person in the series, had been hijacked with his girlfriend two years previously and was eventually hospitalized when he became suicidally depressed (Smith, 2006). Bongi (23) who presented with depression, panic attacks and a general feeling of being ill, had PTSD precipitated by three rape, at the ages of 9,19 and 20 (van der Linde, 2007). Grace (22) came for help with increasing difficulty in concentrating and making decisions, but these symptoms were secondary to PTSD precipitated by her decision to abort an unwanted pregnancy (Boulind \& Edwards, 2008). Sibongeseni (9), who had been raped on two occasions, 
was one of three cases examined by Swartz (2007) for which assessment began but the client did not engage with therapy.

\section{A Model for Evidence-Based Responsive Treatment Planning for PTSD}

From a review of these case studies, a search was made for categories of "clinical focus" (CF), a focus of therapist attention with respect to specific goals. Seven of these were identified. These serve as modules within the overall model and were ordered on three levels based on the stage approach discussed above. Unless the goals of the lower level have been attended to it is usually inappropriate to proceed to a CF at a higher level. The resulting model is presented in Figure 1.

Level 1 (Crisis intervention and stabilization) reflects the need for stabilization before treatment proper can begin. The danger of focusing too early on the active elements of treat- ment has been highlighted by the heated debates on trauma debriefing (van Wyk \& Edwards, 2005). Immediately after a traumatic event, the first priorities are often ensuring safety and practical support (shelter, food, transport). To a large extent the criticisms leveled at some of the debriefing models have been where little or no attention was given to level 1 and level 2 activities, and counsellors were encouraged to go straight into the active treatment module (CF 6) at level 3.

Since the active elements of the treatment (CF 6 and CF 7) call for understanding, systematic committed work, and tolerance of painful emotional states, they cannot be implemented while clients are in crisis, at risk for suicide, behaviourally unstable, abusing alcohol or other substances or so depressed they can hardly function. Crisis intervention may involve engaging social support from family, friends or employers (CF 1), as well as assessing and addressing suicide risk (CF 2) and providing psychoeducation to normalize the triggering of re-experiencing

\section{Figure 1. A Model for Evidence-base Responsive Treatment Planning for PTSD}

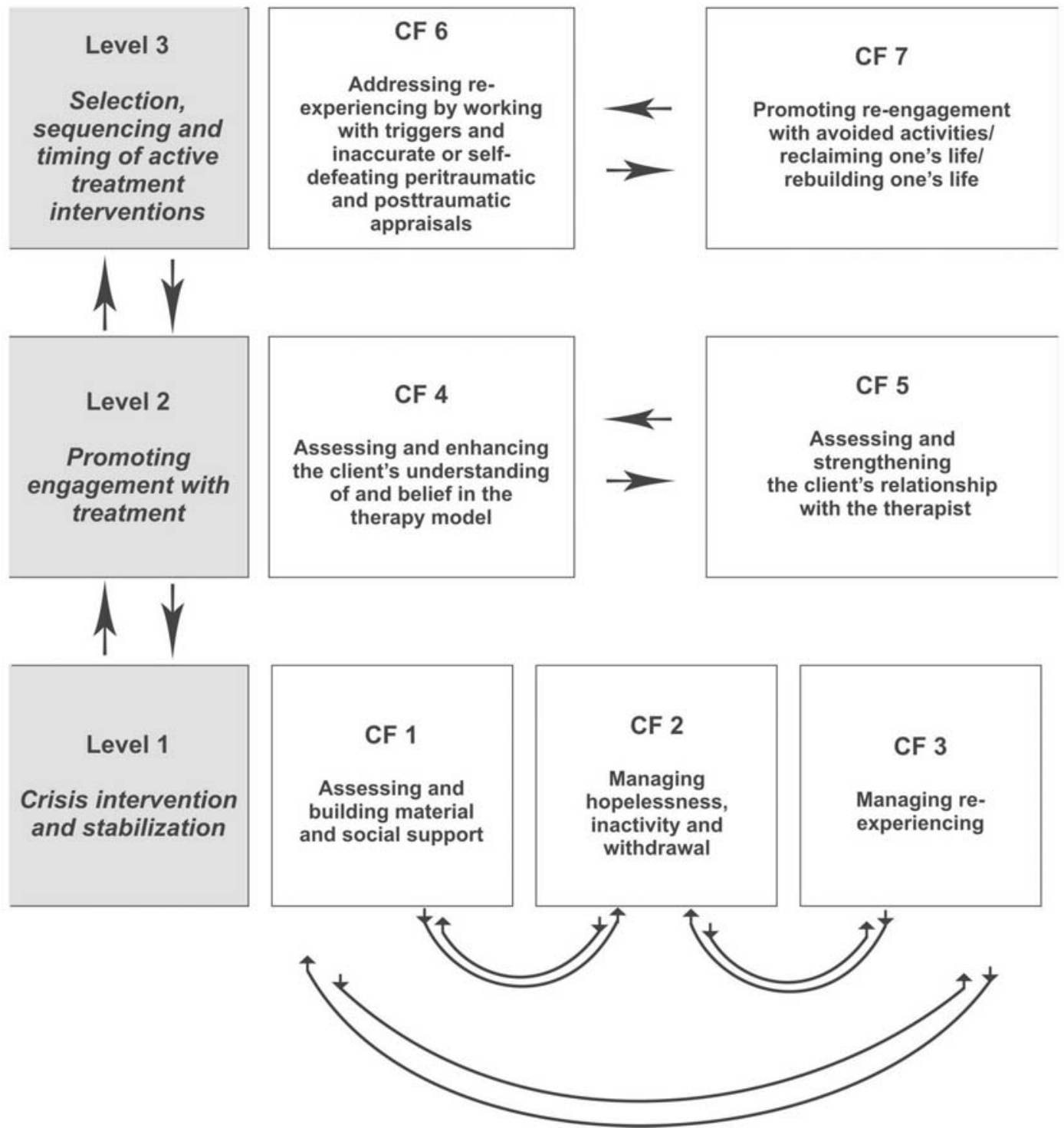


and the origin of associated symptoms (CF 3 ). Although rebuilding one's life (CF 7) is placed at Level 3 , preliminary work on resuming avoided activities can be done right at the beginning. CF 2 thus includes taking steps to help clients who have withdrawn excessively to become more active as avoidance contributes to vulnerability to both PTSD and depression. Ehlers and Clark use the phrase "reclaiming one's life" even for these initial steps and emphasize it throughout treatment. We have not seen cases complicated by substance abuse, but this would also need to be targeted as part of CF 3 . Ehlers and Clark do not pretend to address all aspects of level 1 intervention in detail and, where this is needed, the work of Najavits $(2002,2004)$ provides valuable guidelines.

Social support (CF 1) may also be a prerequisite for working at level 2, especially with children. Thus Leibowitz-Levy (2005, p. 161) observes

there must be a committed caregiver in the child's life who can provide feedback to the therapist, support the child emotionally in the home setting and ensure that the child attends therapy for a number of sessions.

No such adult was available for Sibongiseni (Swartz, 2007). Her mother abused alcohol, behaved sexually in front of her and beat her. After the second rape Sibongiseni was taken in by a caregiver at a care centre who fostered her for a few months. When the caregiver left, Linda, another caregiver, looked after her at her home. Concerned about the rapes and also Sibongiseni's disturbed conduct which included sexually explicit behaviours, she brought her to a psychological service. Linda interpreted while the psychologist interviewed Sibongiseni and agreed to return to give further information. She missed two sessions, which delayed the process and then failed to bring Sibongiseni again. This was partly because of concerns about acting as interpreter for Sibongiseni, but she failed to send Sibongiseni even when the psychologist offered to provide an interpreter and to provide transport. A few weeks later, when contacted on the phone she informed the psychologist that Sibongiseni was now staying with relatives outside of town. Thus Sibongiseni never progressed to level 2.

Level 2 focuses on the client's readiness and motivation to engage with therapy. This is the territory of Prochaska's classic analysis into the stages of precontemplation, contemplation, preparation, action and maintenance. Most of our clients are self-referred so are at least at the contemplation and preparation stage. However, for full engagement with treatment (Level 3) they need to be at the action stage

in which individuals modify their behavior, experiences, and environment in order to overcome their problems. Action involves the most overt behavioral changes and requires considerable commitment of time and energy" (Prochaska \& Norcross, 2001, p. 444).

CF 4 is initiated by the therapist's sharing of the case formulation at the end of the assessment. This is in effect an invitation to the action phase. Some clients, like Grace, Oratilwe and Zanele, respond with eagerness to get going as they feel hopeful that their lives can be changed for the better. Others, however, may be more cautious. They may not fully believe in the treatment model or be too afraid of the painful and overwhelming nature of the emotions that they expect will result from full engagement with treatment. Therapists must monitor this and engage in further psychoeducational or motivational work to address this.
When the rationale for imaginal reliving of the trauma (module CF 6) and what was involved was explained to Bongi, she was not prepared to do it. As therapy unfolded, her therapist regularly encouraged her, but she continued to indicate her unwillingness. In session 8, her therapist showed her a narrative account of a reliving session from Zanele's therapy (Payne, 2007). This motivational work (CF 4) was successful in persuading her to do it at the next session. Bongi began this session by saying she had decided to terminate therapy. Although this turned out to be a joke, it reflected the conflict she felt about revisiting the memory of the most recent rape. At the next session she expressed how difficult the reliving had been in a metaphor:

It's like uprooting trees, taking them out with roots and all; as they are pulled out some damage is done to the earth and a hole is left, but it is for the best (van der Linde, 2007, p. 77).

It was after this session that she began to show a steady reduction in PTSD symptoms, but she still indicated that she would not like to do it again.

Therapists must also monitor clients' degree of engagement with and trust in the therapist (CF 5). Problems in this area need to be identified and actively addressed as they will interfere with effective work at level 3 . Clients may need help in articulating their fears of burdening the therapist or that the therapist will not be able to tolerate the intensity of their pain, or their belief that what they feel is shameful. Where the client brings pre-existing difficulties with insecure attachment, these will also need to be a focus of therapy. Where therapists find themselves fearing the client's reactions or judging them, this needs to be identified and addressed in supervision (Eagle, 2005).

Level 3 is where the active treatment occurs. It is the interventions at this level that tackle the material that has not been integrated into autobiographical memory and promote post-traumatic growth. CF 6 covers the interventions that will (1) increase awareness of how flashbacks and other re-experiencing episodes are triggered and interrupt the triggering process, (2) bring the details of the trauma memory with the associated emotions and beliefs to light, (3) support the client in reprocessing the memory and addressing distressing emotions, and (4) address trauma related beliefs that have overgeneralized (e.g., "nowhere is safe", "no man can be trusted," "my life is ruined."). These interventions will not be described in detail here. Although we drew on techniques described by Ehlers and Clark, many interventions not specifically described by them can contribute to achieving the goals of this module, including the use of drawing, painting, expressive methods, or use of eye-movements to facilitate recall.

Finally, CF 7 covers interventions that enable clients to rebuild their lives. This may involve promoting the restoration of avoided social, occupational and recreational activities (a process begun at level 1). It will include supporting the client in finding positive meaning in what has happened to them in terms of their path in the future and in emerging as a stronger and more resilient person. Summers (1999) suggests that Anna O, the classic case of Breuer and Freud, did not really recover until she left Vienna and established herself with a meaningful identity as a feminist activist and writer. For a comprehensive examination of aspects of posttraumatic growth, the reader is referred to Calhoun and Tedeschi's (2006) comprehensive handbook.

\section{Discussion and Conclusion}

Although the model presented here fits our work using Ehlers and Clark's cognitive therapy approach, its development 
was also consistent with the broader literature already cited (Ehlers \& Clark, 2000; Ford et al, 2005; Herman, 2001; Philips \& Frederick, 1995) and it reflects an emerging consensus about the range of interventions that have a place in the overall treatment of PTSD. Many contemporary CT and CBT treatments are highly integrative. Thus, Kendall et al (2003, p. 82) describe how their work with anxious youth "is guided by an integrationist perspective often labeled cognitive-behavioural." In the same way, Ehlers and Clark's CT integrates much of what has been learned about treating PTSD in the past decades from all traditions. It would be wrong to think of it as a brand of CBT as opposed to "psychodynamic therapy" or "narrative therapy" etc. In so far as it recommends particular methods of formulation and intervention, these are matters of detail within specific modules rather than of the broad structure that the present model offers.

The apparent diversity of treatments for PTSD can be understood as arising from two sources. First, some treatments focus on one CF and de-emphasize others. Psychodynamic approaches may focus more on levels 1 and 2 (as in Labe's case study cited earlier). Other approaches take their names from specific interventions at CF 6 such as exposure, induction of eye-movements, imagery rescripting, cognitive restructuring, or specific expressive techniques such as psychodrama.

By contrast, in the present model there is a focus on the evident commonalities between approaches. By focusing on evidence-based practice, therapist responsiveness, and the stages of therapy, it offers a genuinely integrative perspective. In a formulation driven model such as Ehlers and Clark's, the actual intervention used within a specific module is less important than its appropriateness for the client in achieving a specific goal. Thus, for the task of expressing what happened, reliving of the trauma may be suitable for some clients, while a written or spoken trauma narrative, or drawing the trauma may be more suitable for others. What is important is the function the intervention serves (which is to enable clients to tell the full story of the trauma in a way that accesses the problematic emotional states associated with it). Thus, particularly at CF 6, there is a great deal of technical diversity which is quite consistent with a common understanding of what is involved in resolving trauma memories.

The model is derived from treating fairly simple cases of PTSD (often with comorbid depression) which is the focus of Ehlers and Clark's cognitive therapy which is usually implemented in a treatment of 6 to 30 sessions). Nevertheless it could serve as a general guide for work with more complex cases as it is compatible with the stage models discussed above. Each CF module could be subdivided, or serve as a basis for more detailed guidelines, but, because of space limitations, this article only offers a limited account of interventions within each module. Because each module is focused on a set of goals rather than on particular techniques, the same techniques may be appropriate in different modules. For example, working with someone to expand their social support could be part of CF 1 or CF 7. Some the work of CF 3 may be extended at CF 6. And some of the work in transforming the meaning of emotions in CF 6 will have an impact on the work of CF 7. Thus, within each module, strategic decisions need to be made about the selection and timing of specific interventions. Case formulation, therapist responsiveness and strategic decision making within each module, as observed within our case series, will be examined in a future publication (Edwards, submitted). As it stands, the model may be of value to practitioners in helping them to conceptualize quite quickly what is happening in a particular case and select an appropriate clinical focus. It could be tested and refined by future case based studies examining movements between different areas of clinical focus or elaborating on strategic decision making within a specific one.

Finally, although critics sometimes argue that "Western" models of therapy may not be suitable in Africa (Edwards, 2005a), the present study provides evidence for the cultural generalisability of the Ehlers and Clark model, since all but one of the cases treated were black Africans from Southern Africa. Although developed in the UK, the model was developed in a multicultural context since some cases used in the development of the model were in fact Africans who had moved to London, sometimes as refugees (Personal Communication: Anke Ehlers, July 2008). The data from the present case series confirm the observations made by many clinicians in Africa that evidence-based treatment models developed in first world countries require limited adaptation for use in other cultural contexts provided clinicians show the responsiveness to client context which is, as argued above, a feature of all appropriate psychotherapy.

\section{References}

American Psychological Association (2005). Report of the 2005 Presidential Task Force on Evidence Based Practice. Available at http://www.apa.org/practice/ebpreport.pdf [On-line].

Arnkoff, D. B. (1981). Flexibility in practicing Cognitive Therapy. In G. Emery, S. D. Hollon \& R. C. Bedrosian (Eds.), New Directions in Cognitive Therapy (pp. 203-222). New York: Guilford Press.

Axline, V. M. (1989). Play therapy. Edinburgh: Churchill Livingstone.

Boulind, M., \& Edwards, D. J. A. (2008). The assessment and treatment of post-abortion syndrome: A systematic case study from Southern Africa. Journal of Psychology in Africa, 18, 539-548.

Bowlby, J. (1979). The making and breaking of affectional bonds. London: Tavistock.

Brunink, S. A., \& Schroeder, H. E. (1979). Verbal therapeutic behavior of expert psychoanalytically oriented, gestalt and behavior therapists. Journal of Consulting and Clinical Psychology, 47, 567-574.

Calhoun, L. G., \& Tedeschi, R. G. (2006). Handbook of posttraumatic growth: Research and practice. Mahwah, $\mathrm{NJ}$ : Lawrence Erlbaum.

Chemtob, C. M., Tolin, D. F., Van Der Kolk, B. A., \& Pitman, R. K. (2000). Eye movement desensitization and reprocessing. In E.B. Foa, T. M. Keane \& M. J. Friedman (Eds.), Effective treatments for PTSD: Practical guidelines from the international society for trauma stress studies (pp. 141-151). New York: Guilford.

Clark, D. M., \& Ehlers, A. (2005). Posttraumatic stress disorder: From cognitive theory to therapy. In R. L. Leahy (Ed.), Contemporary cognitive therapy (pp. 141-160). New York: Guilford.

Conway, M. A., \& Pleydell-Pearce, C. W. (2000). The construction of autobiographical memories in the self-memory system. Psychological Review, 27, 261-286.

Dattilio, F. M., \& Norcross, J. C. (2006). Psychotherapy integration and the emergence of instinctual territoriality. Archives of Psychiatry and Psychotherapy, 8, 5-16.

Davidow, A., \& Edwards, D. J. A. (2007). Treatment of PTSD and depression in a black South African rape survivor: $A$ 
case based evaluation of Ehlers and Clark s clinical model. Paper presented at the World Congress of Behavioural and Cognitive Therapies: Barcelona, Spain (July).

Eagle, G. T. (1998). An integrative model for brief term intervention in the treatment of psychological trauma. International Journal of Psychotherapy, 3, 1-11.

Eagle, G. T. (2000). The shattering of the stimulus barrier: The case for an integrative approach for short-term treatment for psychological trauma. Journal of Psychotherapy Integration, 10, 301-324.

Eagle, G. T. (2005). Grasping the thorn: The impact and supervision of post-traumatic stress therapy in the South African context. Journal of Psychology in Africa, 15, 197-207.

Edwards, D. J. A. (2005a). Critical perspectives on research on post-traumatic stress disorder and implications for the South African context. Journal of Psychology in Africa, 15, 117-124.

Edwards, D. J. A. (2005b). Treating PTSD in South African contexts: A theoretical framework and model for the development of evidence-based practice. Journal of Psychology in Africa, 15, 209-220.

Edwards, D. J. A. (Submitted). Using systematic case studies to study therapist responsiveness: Examples from a case series of PTSD treatments. Pragmatic Case Studies in Psychotherapy.

Edwards, D. J. A., Dattilio, F., \& Bromley, D. B. (2004). Developing evidence-based practice: The role of case-based research. Professional Psychology: Research and Practice, 35, 589-597.

Edwards, D. J. A., Sakasa, P., \& van Wyk, G. (2005). Trauma, resilience and vulnerability to PTSD: A review and clinical case discussion. Journal of Psychology in Africa, 15, 143-153.

Eells, T. D. (1997). Handbook of psychotherapy case formulation. London: Guilford.

Eells, T. D., Lombart, K. G., Kendjelic, E. M., Turner, L. C., \& Lucas, C. P. (2005). The quality of psychotherapy case formulations: A comparison of expert, experienced, and novice cognitive-behavioral and psychodynamic therapists. Journal of Consulting and Clinical Psychology, 73, 579-589.

Ford, J. D., Courtois, C. A., Steele, K., Van Der Hart, O., \& Nijenhuis, E. (2005). Treatment of complex traumatic self-dysregulatiion. Journal of Traumatic Stress, 18, 437-447.

Foster, D. (1998). Social Psychology. In D. A. Louw \& D. J. A. Edwards (Eds.). Psychology: An introduction for students in southern Africa (2nd ed.). Johannesburg: Heinemann.

Ehlers, A., \& Clark, D. M. (2000). A cognitive model of posttraumatic stress disorder. Behaviour Research and Therapy, 38, 319-345.

Ehlers, A., Clark, D. M., Hackmann, A., McManus, F., \& Fennell, M. (2005). Cognitive therapy for post-traumatic stress disorder: development and evaluation. Behaviour Research and Therapy, 43, 413-431.

Erdelyi, M. H. (1985). Psychoanalysis: Freud's cognitive psychology. New York: Freeman.

Fishman, D. B. (2005). Editor's Introduction to PCSP - From Single case to database: A new method for enhancing psychotherapy practice. Pragmatic Case Studies in Psychotherapy [Online], 1, Module 1, Article 2. Available: http://pcsp.libraries.rutgers.edu.

Gilbert, P., \& Leahy, R. (2007). Introduction and overview: Basic issues in the therapeutic relationship. In P.Gilbert \& R. Leahy
(Eds.), The therapeutic relationship in the cognitive-behavioral psychotherapies (pp. 3-23). London: Routledge.

Goodheart, C. D. (2005). Placing psychotherapy case studies within the framework of the APA evidence-based practice in psychology (EBPP) model. Pragmatic Case Studies In Psychotherapy [on line], 1, Module 3, Article 2. Available: http://pcsp.libraries.rutgers.edu.

Grunert, B. K., Weis, J. M., Smucker, M., \& Christianson, H. F. (2007). Imagery rescripting and reprocessing therapy after failed exposure for post-traumatic stress disorder following industrial injury. Journal of Behavior Therapy and Experimental Psychiatry, 38, 317-328.

Guidano, V. F., \& Liotti, G. (1983). Cognitive processes and emotional disorders. New York: Guilford.

Herman, J. L. (2001). Trauma and recovery: From domestic abuse to political terror. London: Pandora.

Horowitz, M. J. (2001). Stress response syndromes: Personality styles and interventions. (4th ed.) Northvale, NJ: Jason Aronson.

Kaduson, H. G., \& Schaefer, C. E. (2003). 101 favorite play therapy techniques. Northvale, NJ: Jason Aronson.

Karpelowsky, B. J., \& Edwards, D. J. A. (2005). Trauma, imagery and the therapeutic relationship: Langu's story. Journal of Psychology in Africa, 15, 185-195.

Kendall, P. C., Aschenbrand, S. G., \& Hudson, J. L. (2003). Child-focused treatment of anxiety. In A.E. Kazdin \& R. Weisz (Eds.), Evidence-based psychotherapies for children and adolescents (pp. 81-100). New York: Guilford.

Knell, S.M. (1993). Cognitive-behavioral play therapy. Northvale, $\mathrm{NJ}$ : Jason Aronson.

Kubany, E. S., Hill, E. E., Owens, J. A., Iannce-Spencer, C., McCaig, M. A., Tremayne, K. J., et al. (2004). Cognitive trauma therapy for battered women with PTSD (CTT-BW). Journal of Consulting and Clinical Psychology, 72, 3-18.

Labe, D. (2005). Psychotherapy for post-traumatic stress disorder in a young rape survivor: A case study. Journal of Psychology in Africa, 15, 177-184.

Langs, R. (1996). The evolution of the emotion-processing mind. London: Karnac Books.

Leibowitz-Levy, S. (2005). The role of brief term interventions with South African child trauma survivors. Journal of Psychology in Africa, 15, 155-163.

Liotti, G. (2007). Internal working models of attachment in the therapeutic relationship. In P. Gilbert \& R. Leahy (Eds.), The therapeutic relationship in the cognitive-behavioral psychotherapies (pp. 143-161). London: Routledge.

Lohr, J. M., Lilienfeld, S. O., Tolin, D. F., \& Herbert, J. D. (1999). Eye movement desensitization and re-processing: An analysis of specific versus non-specific treatment factors. Journal of Anxiety Disorders, 13, 187-207.

McDonagh, A., Friedman, M., McHugo, G., Ford, J., Sengupta, A., Mueser, K., et al. (2005). Randomized trial of cognitive-behavioural therapy for chronic posttraumatic stress disorder in adult female survivors of childhood sexual abuse. Journal of Consulting and Clinical Psychology, 73, 515-524.

Najavits, L. M. (2002). Seeking safety: A treatment manual for PTSD and substance abuse. New York: Guilford.

Najavits, L. M. (2004). Seeking safety: A new psychotherapy for posttraumatic stress disorder and substance use disorder. In P. Ouimette \& P. Brown (Eds.), Trauma and substance 
abuse: Causes, consequences and treatment of co-morbid disorders. Washington, DC: American Psychological Association.

Newman, C. F. (2007). Cognitive therapy with difficult to engage clients. In P. Gilbert \& R. Leahy (Eds.), The therapeutic relationship in the cognitive-behavioral psychotherapies (pp. 165-184). London: Routledge.

Paivio, S. C., \& Nieuwenhuis, J. A. (2001). Efficacy of emotion focused therapy for adult survivors of child abuse: A preliminary study. Journal of Traumatic Stress, 14, 115-133.

Payne, C., \& Edwards, D. J. A. (2007). Breaking the silence of child rape. Paper presented at the 8th national conference of the South African Professional Society on the Abuse of Children, Pretoria (May).

Payne, C. (2006). Breaking the silence: Zanele's journey of recovery. Unpublished masters research report, Rhodes University, Grahamstown.

Persons, J. B., \& Bertagnolli, A. (1999). Inter-rater reliability of cognitive-behavioural case formulations of depression: a replication. Cognitive Therapy And Research, 23, 271-283.

Persons, J. B., Curtis, J. T., \& Silberschatz, G. (1991). Psychodynamic and cognitive-behavioral formulations of a single case. Psychotherapy, 28, 608-617.

Phillips, M., \& Frederick, C. (1995). Healing the divided self: Clinical and Ericksonian hypnotherapy for posttraumatic and dissociative conditions. New York: W. W. Norton.

Prochaska, J. O., \& Norcross, J. C. (2001). Stages of change. Psychotherapy, 38, 443-448.

Pynoos, R. S., \& Eth, S. (1986). Witness to violence: The child interview. Journal of the American Academy Child Psychiatry, 25, 306-319.

Resick, P. A., Nishith, P., Astin, A. C., Weaver, W. L., \& Feuer, C. A. (2002). A comparison of cognitive-processing therapy with prolonged exposure and waiting condition for the treatment of chronic posttraumatic stress disorder in female rape victims. Journal of Consulting and Clinical Psychology, 70, 867-879.

Ronen, T. (1997). Cognitive developmental therapy with children. New York: Wiley.

Roth, A. D., \& Pilling, S. (2008). Using an evidence-based methodology to identify the competences required to deliver effective cognitive and behavioural therapy for depression and anxiety disorders. Cognitive and Behavioural Psychotherapy, 36, 129-147.

Sackett, D., Rosenburg, W., Gray, J., Haynes, R., \& Richardson, W. (1996). Evidence-based medicine: What it is and what it isn't. British Medical Journal, 312, 71-72.

Safran, J. D. (1984). Assessing the cognitive interpersonal cycle. Cognitive Therapy and Research, 8, 333-348.

Safran, J. D., \& Muran, J. C. (2000). Resolving therapeutic alliance ruptures: diversity and integration. Journal of Clinical Psychology, 56, 233-243.

Safran, J. D., \& Segal, Z. V. (1996). Interpersonal process in cognitive therapy. Northvale, NJ: Jason Aronson.

Salkovskis, P. M. (2002). Empirically grounded clinical interventions: Cognitive-behavioral therapy progresses through a multi-dimensional approach to clinical science. Behavioural and Cognitive Psychotherapy, 30, 1-10.

Schaefer, C. E. (1993). The therapeutic powers of play. Northvale, NJ: Jason Aronson.
Schaefer, C. E., \& Cangelosi, D. M. (2002). Play therapy techniques. (2nd ed.) Northvale, NJ: Jason Aronson.

Schottenbauer, M. A., Glass, C. R., \& Arnkoff, D. B. (2008). Contributions of psychodynamic approaches to treatment of PTSD and trauma: A review of the empirical treatment and psychopathology literature. Psychiatry: In terpersonal and Biological Processes, 71, 13-34.

Smith, T.A. (2006). Frozen in time to reclaiming one's life: The evaluation of the Ehlers and Clark cognitive therapy model in the assessment and treatment of a hijacking survivor. Unpublished masters research report, Rhodes University, Grahamstown.

Smucker, M. R., Grunert, B. K., \& Weis, J. M. (2003). Posttraumatic stress disorder: A new algorithm treatment model. In R.L. Leahy (Ed.), Roadblocks in cognitive-behavioral therapy: Transforming challenges into opportunities for change (pp. 175-194). New York: Guilford.

Steele, K., Van Der Hart, O., \& Nijenhuis, E. (2005). Phase-oriented treatment of structural dissociation in complex traumatization: Overcoming trauma-related phobias. Journal of Trauma and Dissociation, 6, 11-53.

Stiles, W. B., Honos-Webb, L., \& Surko, M. (1998). Responsiveness in psychotherapy. Clinical Psychology: Science and Practice, 5, 439-458.

Summers, F. L. (1999). Transcending the self: An object relations model of psychoanalytic therapy. Hillsdale, NJ: Analytic Press.

Swartz, K. (2007). Contextual obstacles to the delivery of effective psychological treatment of PTSD in a South African community setting. Unpublished masters research report, Rhodes University, Grahamstown.

van der Linde, F. (2007). Past trauma, anxious future: $A$ case-based evaluation of the Ehlers and Clark model for PTSD applied in Africa. Unpublished masters research report, Rhodes University, Grahamstown.

van Wyk, G., \& Edwards, D. J. A. (2005). From trauma debriefing to trauma support: The South African experience of responding to individuals and communities in the aftermath of traumatizing events. Journal of Psychology in Africa, 15, 135-142.

Waller, G., Kennerley, H., \& Ohanian, V. (2007). Schema-focused cognitive-behavioural therapy for eating disorders. In J. Rodin, P. L. du Toit, D. J. Stein, \& J. E. Young (Eds.), Cognitive Schemas and Core Beliefs in Psychological Problems: A Scientist-Practitioner Guide (pp. 139-175). Washington, DC: American Psychological Association.

\section{Acknowledgements}

1. Supported by grants from the Rhodes University Joint Research Committee and the National Research Foundation.

2. Some of this material was originally presented at a panel entitled "Finding gold in the psychotherapy case study: Using "pragmatic case studies" to explore the quality, process, and effectiveness of case formulation in therapy" at the conference of the Society for Psychotherapy Research in Barcelona, June 2007. The author extends his thanks to the panel organizer, Dan Fishman for stimulating the ideas which led to this paper. 